\title{
Explosion venting of hydrogen-air mixtures from a duct to a vented vessel
}

\author{
Hongwei Li ${ }^{\text {a }}$, Jin guo ${ }^{\text {b,c, }}$, Fuqiang Yang ${ }^{\text {b }}$, Changiian Wang ${ }^{\mathrm{d}}$, Jiaqing Zhang ${ }^{\mathrm{e}}$, Shouxiang Lu ${ }^{\mathrm{c}, *}$ \\ ${ }^{a}$ School of Chemical Engineering, Anhui University of Science and Technology, Huainan 232001,
}

\author{
Anhui China \\ ${ }^{b}$ College of Environment and Resources, Fuzhou University, Fuzhou 350116, PR China \\ ${ }^{c}$ State Key Laboratory of Fire Science, University of Science and Technology of China, Hefei 230027, \\ PR China \\ ${ }^{d}$ School of Civil Engineering, Hefei University of Technology, Hefei 230009, PR China \\ ${ }^{e}$ Anhui Electric Power Research Institute, Hefei 230601, PR China
}

Corresponding Author

Jin Guo guojin@fzu.edu.cn

College of Environment and Resources, Fuzhou University, Fuzhou, Fujian 350116, PR China

Shouxiang Lu sxlu@ustc.edu.cn

State Key Laboratory of Fire Science, University of Science and Technology of China, Hefei, Anhui 230027, PR China 


\section{Abstract:}

Experiments were conducted on the vented explosion of hydrogen-air mixtures from a 1.5-m-long duct to a vented cylindrical vessel to investigate the effects of vent burst pressure and an obstacle in a duct on the process of explosion venting. Turbulent pressure oscillation owing to a pressure wave moving back and forth in a duct and vessel was observed for unvented explosions. For explosion venting from a duct to a vessel, the maximum reduced overpressure increased with an increase in the vent cover thickness. Although the maximum explosion overpressure was significantly less compared to an unvented explosion, it was still too high to be effective; therefore, it is recommended to fit an explosion vent in the duct. An obstacle installed in a duct significantly affected the explosion overpressure, which first increased and then decreased with an increase in the blockage ratio and the external flow field. Several pressure peaks resulting from different pressure waves were observed.

Keywords: Explosion venting; Overpressure; Flame; Duct; Obstacle 


\section{Introduction}

Hydrogen is widely used in industrial applications, and hydrogen explosion hazards are critically important because of the wide flammable range, low ignition energy, and high burning rate. Therefore, explosion vents are extensively employed to protect equipment against excessive internal explosion pressures by means of effective pressure relief. Explosion venting of hydrogen-air mixtures has been experimentally and numerically investigated, and the parameters of ignition position [1-8], vent area $[1-5,8,9]$, hydrogen concentration $[1,4,5,10]$, vessel volume $[2,8]$, pre-ignition turbulence $[1,6,11]$, obstruction $[2,4,5,10]$, and vent burst pressure $[12,13]$ have been investigated.

In most previous research, only a single vessel was used to investigate the phenomena of vented hydrogen-air deflagrations. However, vessels interconnected by pipes are very common in the industry, and the fact that flames can spread from one vessel to another through the pipes was observed to significantly affect the maximum internal overpressure. Holbrow et al. [14] investigated explosion venting of dust in two vessels with different volumes connected with a pipe and observed that the passage of flames from the primary ignition vessel resulted in a secondary explosion that produced a much higher pressure than expected from a vented single vessel and that the pressure enhancement was greatest when the primary ignition occurred in the larger of the two vessels. Zhang et al. [15] investigated the vented explosion of methane-air mixtures in a confinement similar to that of Holbrow [14], and their experimental results demonstrated that explosion transmission from a large vessel to a small vessel caused a poorer venting effect and the longer is the pipe, the larger is the peak pressure. Liang [16] investigated vented lean hydrogen-air deflagration in rectangular vessels configured with single and multiple chambers, and higher overpressure was measured for the tests involving more chambers. In other research, a vessel with a connected duct was employed to study the 
effect of the relief duct on the process of explosion venting [17-22], and it was observed that the use of a relief duct often significantly increased the internal explosion overpressure.

Although explosion of dust [14] and methane [15] in interconnected vessels have been investigated, the flame behavior and pressure build-up of vented hydrogen-air deflagration are not well understood, and the effectiveness of explosion venting is not well known. Hydrogen is more reactive and more prone to accelerate, resulting in higher overpressure and even worse cause a transition from deflagration to detonation under suitable conditions $[23,24]$. In this study, experiments of vented hydrogen-air deflagration from a 1.5-m-long duct to a vented vessel were performed to investigate the flame behavior and pressure build-up within and outside a confinement. In some tests, an orifice plate fitted in the duct was used to simulate the effect of a valve installed in pipes that connect vessels on explosion venting.

\section{Experimental}

Fig.1 shows the vented enclosure used in the study. The cylindrical vessel had two 10-cm-long necks at its waist, one of which was connected to a 1.5 -m-long duct containing three 0.5 -m-long short ducts, and the other was sealed with a vent cover. The inner diameter and length of the cylindrical vessel was $25 \mathrm{~cm}$, and the square cross section of the necks and ducts was $7 \times 7 \mathrm{~cm}$. Quartz windows were fitted into the cylindrical vessel and duct as shown in Fig. 1 to allow optical access necessary for a Schlieren system.

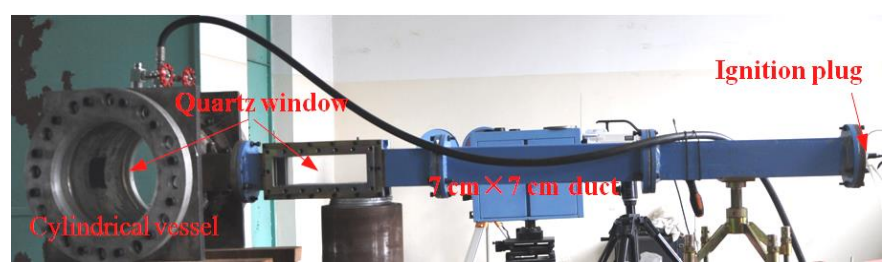

Fig. 1. Photograph of 1.5-m-long duct and vented vessel.

The hydrogen-air mixture was ignited at the end of the duct using an ignition plug mounted at the 
end of the duct, and the ignition energy was maintained at approximately $500 \mathrm{~mJ}$. The measuring systems and experimental procedures were quite similar to our earlier work [13,22]. The flame images were captured by a high-speed Schlieren system. Three piezoelectric pressure sensors, $\mathrm{PS}_{1}-\mathrm{PS}_{3}$, were employed to record pressure histories. $\mathrm{PS}_{1}$ was mounted $60 \mathrm{~cm}$ from the ignition plug, $\mathrm{PS}_{2}$ was flush with the inner surface of the wall, and $\mathrm{PS}_{3}$ was mounted $60 \mathrm{~cm}$ from the vent cover on the axis of venting. And pressure sensors were coated with a thin layer of silicon grease to avoid thermal effects on the pressure measurements.

Our focus was the effects of vent burst pressure and an obstacle fitted $50 \mathrm{~cm}$ from the ignition plug on explosion venting. Experiments with vents sealed by a blind flange (unvented explosion) were also conducted to verify the effectiveness of explosion venting. There was no obstacle in the tests of varying vent burst pressure, and paper with thicknesses $(\delta)$ from 0.05 to $0.3 \mathrm{~mm}$ was used as a diaphragm to seal the vent. In the tests with an obstacle, the thickness of the vent cover was $0.1 \mathrm{~mm}$. An orifice plate with a central square hole was fitted $50 \mathrm{~cm}$ from the ignition plug to serve as an obstacle. The cross sections of the square holes were $1.8 \times 1.8 \mathrm{~cm}^{2}, 2.5 \times 2.5 \mathrm{~cm}^{2}, 3.5 \times 3.5 \mathrm{~cm}^{2}, 5 \times 5$ $\mathrm{cm}^{2}$, and $7 \times 7 \mathrm{~cm}^{2}$, resulting in blockage ratios $(B R)$ of $0.93,0.87,0.75,0.49$, and 0 , respectively. Here, $B R$ denotes the ratio of the blocked cross-sectional area to the entire area of the duct.

In this study, a 30\% hydrogen-air mixture was used to simulate the most dangerous case. All tests were performed three times at 1-atm initial pressure and temperature of $280 \mathrm{~K}$. The reproducibility of the pressure profiles, peak overpressures, and flame behaviors was good.

\section{Results and discussion}

\subsection{Typical pressure profile in unvented vessel}

As shown in Fig. 2, in the experiments with vents sealed by a blind flange (unvented explosion), 
turbulent pressure oscillation, which was absent in the cylindrical vessel alone, occurred in the duct $\left(\mathrm{PS}_{1}\right)$ and the vessel $\left(\mathrm{PS}_{2}\right)$, as discovered for methane-air [25] and dust explosions [26] in vessels connected by pipes. Fig. 2 shows that $\mathrm{PS}_{1}$ and $\mathrm{PS}_{2}$ oscillated at nearly the same frequency, which decreased from approximately $160 \mathrm{~Hz}$ to $100 \mathrm{~Hz}$, and the oscillation amplitude also decreased gradually. In the confinement containing the 1.5-m-long duct and vessel, the maximum overpressure in the duct (PS1) was $950 \mathrm{kPa}$, and the maximum overpressure of $700 \mathrm{kPa}$ in the vessel (PS2) was higher than that in the cylindrical vessel alone as shown in Fig. 2.

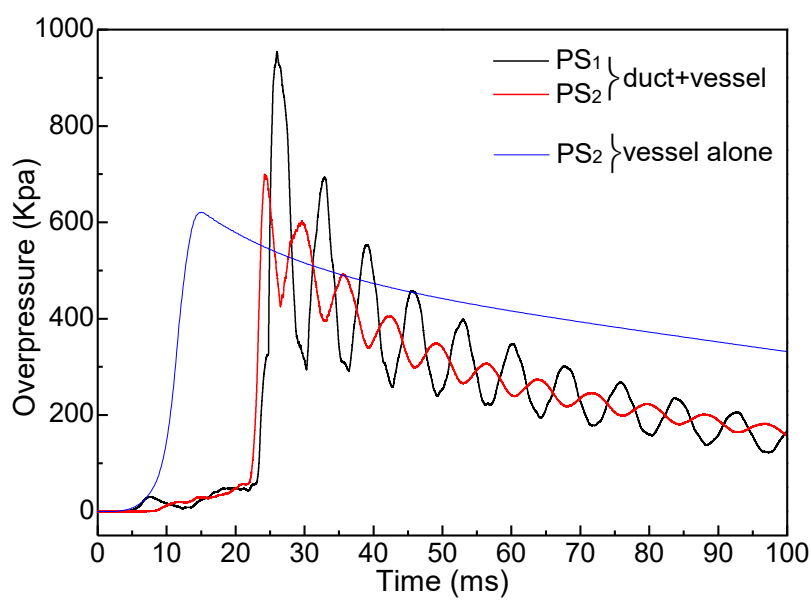

Fig. 2. Pressure profile of unvented explosion.

The above phenomena may be caused by pressure waves moving back and forth in the duct and the vessel, as shown in Fig. 3. After ignition, the flame accelerates in the duct and enters the cylindrical vessel at a high speed, causing a very high explosion overpressure in the vessel compared to the constant volume explosion in the vessel alone, and a pressure wave forms moving from the vessel to the duct. As shown in Fig. 3, the pressure wave passing through the quartz window of the duct was recorded via a high-speed Schlieren system at time $t+4.1 \mathrm{~ms}$. The pressure wave (incident wave) reflected on the rigid surface of the steel blind plate fitted at the end of the duct $[27,28]$ created the first pressure peak in the duct as high as $950 \mathrm{kPa}$, as shown in Fig. 2. 


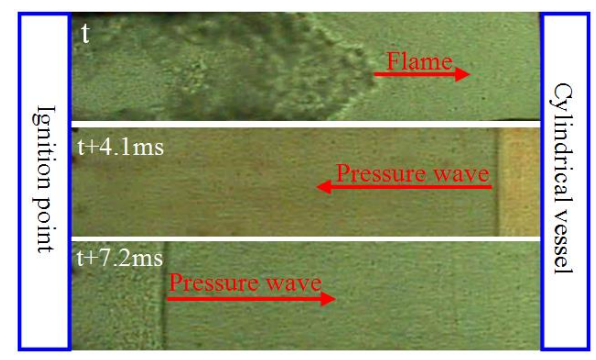

Fig. 3. Flame and pressure wave propagating in duct.

The reflected pressure wave moving towards the vessel passes through the quartz window again at approximately $t+7.2 \mathrm{~ms}$, as shown in Fig. 3. When the wave enters the cylindrical vessel, it is reflected at the vessel wall and moves from the vessel to the duct. The gradually decaying pressure waves moving back and forth in the duct and vessel were observed several times in the experiments.

\subsection{Effect of vent burst pressure}

Compared to unvented explosions, turbulent pressure oscillation was absent in the vented explosions. As shown in Fig. 4, the explosion overpressures in the vessel and duct reached their maximum values successively and then decreased to an ambient pressure in dozens of milliseconds. The maximum reduced overpressure in the duct $\left(\mathrm{PS}_{1}\right)$ was higher than that in the vessel $\left(\mathrm{PS}_{2}\right)$ as a result of the pressure wave shown in Fig. 3 but the pressure wave decayed quickly because of the venting; therefore, no turbulent pressure oscillation was observed.

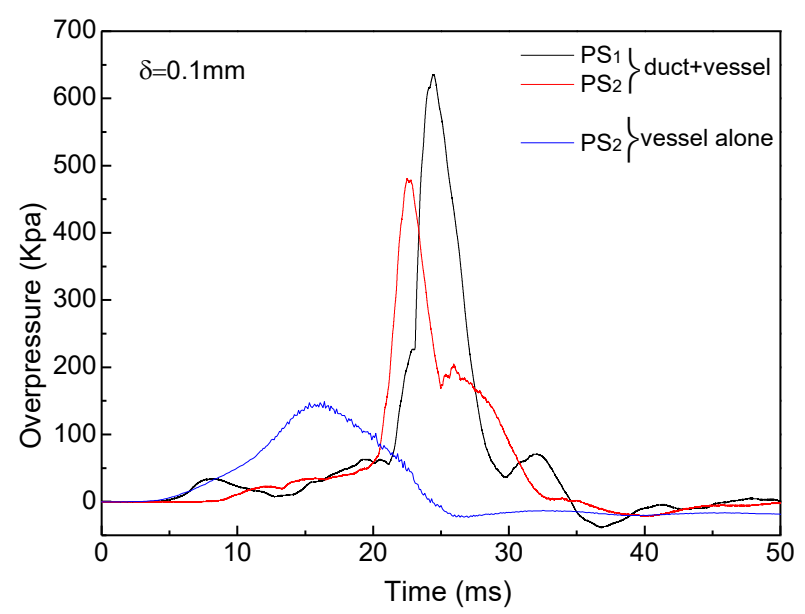

Fig. 4. Typical pressure profile for vented explosion with and without 1.5-m-long duct. 
The maximum reduced overpressure in both the vessel and the duct increased with an increase in $\delta$, similar to the explosion venting in the cylindrical vessel alone [13]. As shown in Fig. 5, with $\delta$ increasing from 0.05 to $0.3 \mathrm{~mm}$, the maximum $\mathrm{PS}_{2}$ increased to $760 \mathrm{kPa}$ and the maximum $\mathrm{PS}_{2}$ increased to $620 \mathrm{kPa}$, which approximates the maximum explosion overpressure in the unvented vessel.

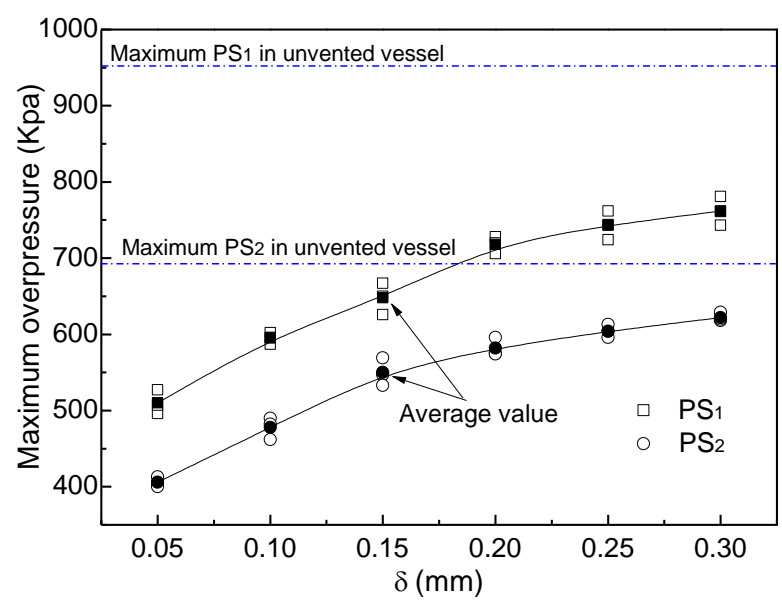

Fig. 5. Maximum overpressure vs. $\delta$.

Obviously, the maximum reduced overpressure in both the duct and the vessel was too high to ensure an effective explosion venting measurement. Taking $\delta=0.1 \mathrm{~mm}$ as an example, Fig. 4 shows that the maximum reduced overpressure in the duct and vessel confinement was more than three times that of the cylindrical vessel alone, which was caused by flame acceleration in the duct.

As shown in Fig. 6, after the flame accelerated in the 1.5-m-long duct, it entered the cylindrical vessel in approximately $200 \mathrm{~m} / \mathrm{s}$ and the explosion vessel developed quickly and lasted only a few milliseconds. However, for the explosion venting in the cylindrical vessel alone, the flame propagated at a much slower speed, and as a result the maximum reduced overpressure was much lower. Therefore, in vessels connected with pipes, it is necessary to place explosion vents on the duct beside the vessel to prevent flame acceleration and reduce explosion overpressure [29]. 


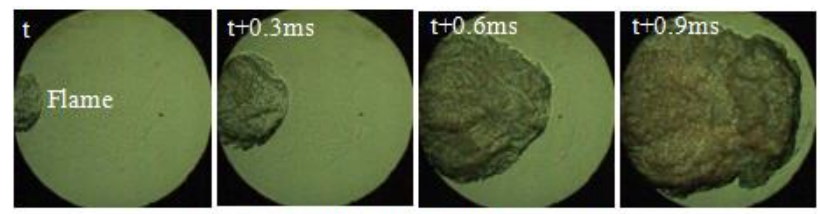

(a) 1.5-m-long-duct and cylindrical vessel

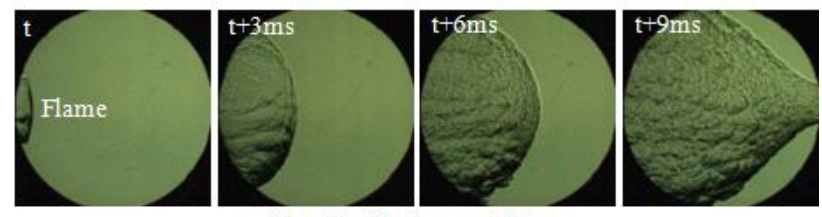

(b) Cylindrical vessel alone

Fig. 6. Flame propagating in cylindrical vessel with and without 1.5 -m-long duct ( $\delta=0.1 \mathrm{~mm})$.

\subsection{Effect of an obstacle in duct}

An orifice plate fitted $0.5 \mathrm{~m}$ from the ignition plug was used to simulate the effect of valves installed in pipes on explosion venting, and the $B R$ parameter was the focus. The typical pressure profiles for $B R=0$ and 0.87 are given in Fig. 7. Here, $B R=0$ means no orifice plate was used. Compared with $B R=0$, Fig. 7 shows that the explosion pressure rose earlier and the maximum reduced overpressure in both the duct and the vessel was higher when the orifice plate was present because the orifice plate caused the flame to accelerate [28,30-32].

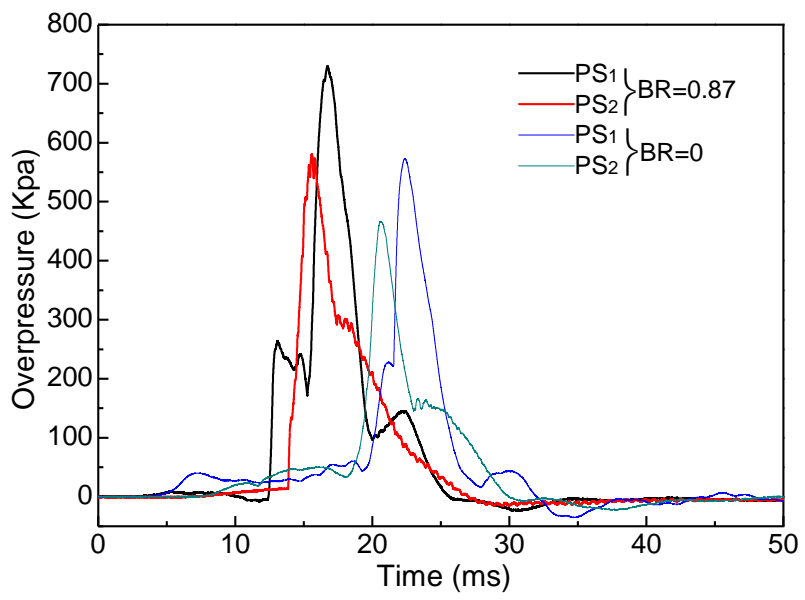

Fig. 7. Typical pressure profiles for $B R=0$ and 0.87 .

For $B R=0$, the average speed was about $100 \mathrm{~m} / \mathrm{s}$ when the flame passed through the quartz window but the flame speed increased to approximately $600 \mathrm{~m} / \mathrm{s}$ for $B R=0.87$. The flame propagated at such a high speed that pressure waves formed ahead of it, as shown in Fig. 8. The 
pressure wave entered the cylindrical vessel at a speed of approximately $900 \mathrm{~m} / \mathrm{s}$, followed by unburned gas mixture and then flame as shown in Fig. 9. The explosion lasted a millisecond; as the burned gas mixtures could not be vented in such a short time, the maximum reduced overpressure was very high.

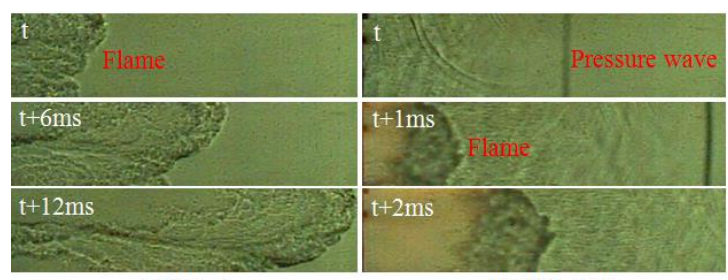

(a) $\mathrm{BR}=0$

(b) $\mathrm{BR}=0.87$

Fig. 8. Flame and pressure wave propagating in duct.
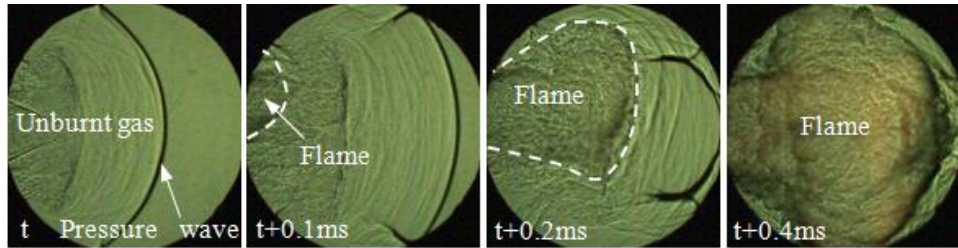

Fig. 9. Flame and pressure wave propagating in vessel $(B R=0.87)$.

Experimental results show that $B R$ has a significant effect on the maximum reduced overpressure.

As shown in Fig. 10, the maximum reduced overpressure in both the duct and the vessel increased as $B R$ increased from 0 to 0.87 and then decreased with a further increase in the $B R$.

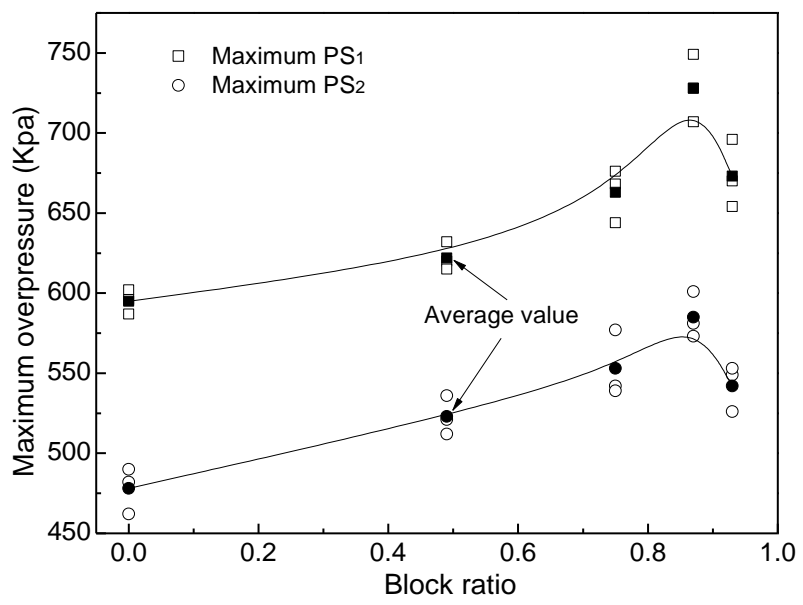

Fig. 10. Maximum reduced overpressure vs. $B R$.

\subsection{Typical external flow field}


For $B R=0$ (no obstacle in duct), the unburned gas mixture was vented after the vent cover burst to form an external combustible cloud as shown in Fig. 11(a). External explosion occurred shortly after the combustible cloud was ignited by the flame rushing out from the vent, and a pressure wave formed, which resulted in the dominant pressure peak shown in Fig. 12.

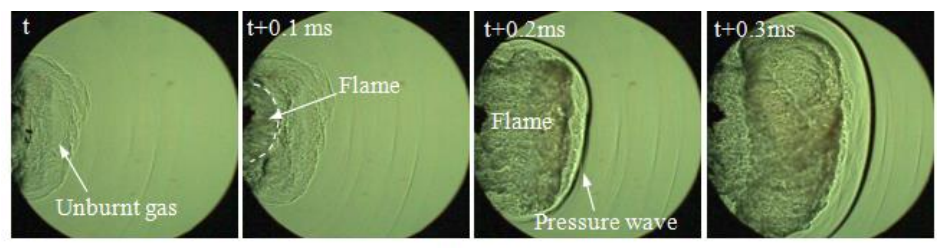

(a) $\mathrm{BR}=0$

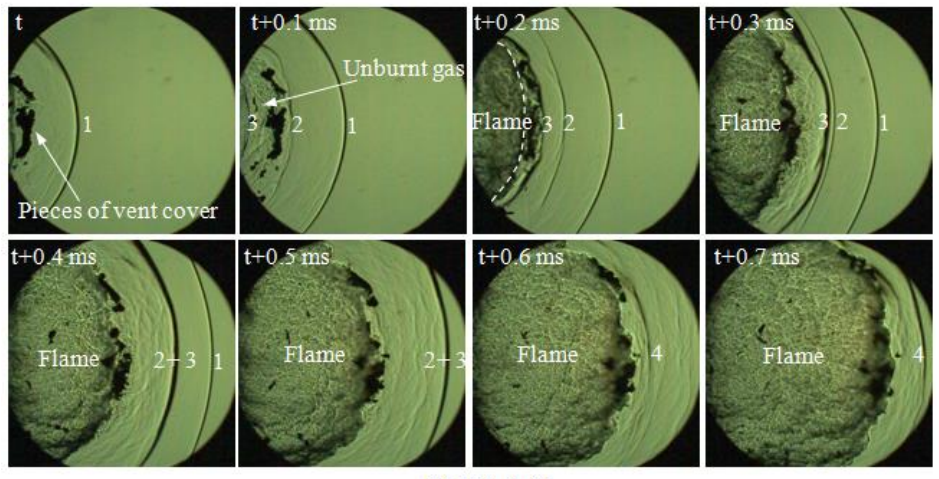

(b) $\mathrm{BR}=0.87$

Fig. 11. Schlieren images of external flow field $(\delta=0.1 \mathrm{~mm})$.

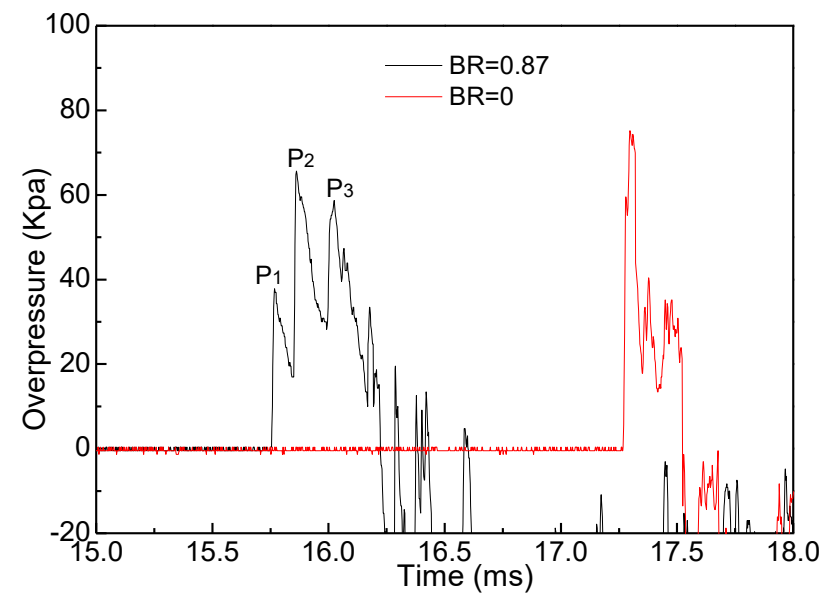

Fig. 12. Typical external pressure profile recorded by $\mathrm{PS}_{3}(\delta=0.1 \mathrm{~mm})$.

Compared with the case of $B R=0$, experimental results show that several pressure waves formed outside the vent and several pressure peaks appeared when the duct was blocked. Taking $B R=0.87$ as an example, Fig. 11(b) shows that three pressure peaks can be identified as a result of the different 
pressure waves shown in Fig. 12.

In Fig. 12, pressure wave 1 is part of the pressure wave that formed in the duct (pressure wave shown in Fig. 8), entered the cylindrical vessel (pressure wave shown in Fig. 9), and rushed out of the vessel though the vent. Pressure wave 1 caused the first pressure peak $\mathrm{P}_{1}$. Pressure wave 2 was caused by the rapid compression of the unburned gas mixture to ambient air, and pressure wave 3 resulted from the explosion in the cylindrical vessel. As shown in Fig. 12, pressure wave 3 caught up with pressure wave 2 and together they propagated forward to cause the second pressure peak $\mathrm{P}_{2}$. Pressure wave 4, which formed from the external explosion [22], led to the third pressure peak $\mathrm{P}_{3}$.

\section{Conclusions}

Flame behavior and pressure build-up was experimentally investigated during explosion venting of hydrogen-air mixtures from a 1.5-m-long duct to a vented cylindrical vessel. The effect of vent burst pressure and an obstacle in a duct on flame propagation and pressure history was investigated. The major conclusions drawn under current experimental conditions are summarized below.

For unvented explosion, turbulent pressure oscillation can occur in both a vessel and a duct because of the pressure wave moving back and forth in the duct and vessel; the oscillation frequency and amplitude decay gradually.

For explosion venting from a duct to a vessel, the maximum reduced overpressure increases with an increase in the thickness of the vent cover. Although the maximum explosion overpressure is significantly reduced compared to that of an unvented explosion, it is still too high to be effective therefore, fitting an explosion vent in a duct is recommended.

An obstacle significantly affects the explosion overpressure, which first increases and then decreases with an increase in the blockage ratio and the external flow field; several pressure peaks 
resulted from different pressure waves.

\section{Acknowledgments}

This study is supported by the National Key Research and Development Program of China (No. 2016YFE0113400), EU HySEA project (No. 671461), the National Natural Science Foundation of China (Grant No.51741402) and the Open Fund of State Key Laboratory of Fire Science of China (No. HZ2017-KF04).

\section{References}

[1] Kumar RK, Dewit WA, Greig DR. Vented explosion of hydrogen-air mixtures in a large volume. Combust Sci Technol 1989; 66(4-6): 251-266.

[2] Chao J, Bauwens CR, Dorofeev SB. An analysis of peak overpressures in vented gaseous explosions. P Combust Inst 2011; 33(2):2367-2374.

[3] Rocourt X, Awamat S, Sochet I, Jallais S. Vented hydrogen-air deflagration in a small enclosed volume. Int J Hydrogen Energ 2014; 39(35): 20462-20466.

[4] Kuznetsov M, Friedrich A, Stern G, Kotchourko N, Jallais S, L'Hostis B. Medium-scale experiments on vented hydrogen deflagration. J Loss Prevent Proc 2015; 36:416-428.

[5] Bauwens CR, Chao J, Dorofeev SB. Effect of hydrogen concentration on vented explosion overpressures from lean hydrogen-air deflagrations. Int J Hydrogen Energ 2012; 37 (22): 1759917605.

[6] Bauwens CR, Dorofeev SB. Effect of initial turbulence on vented explosion overpressures from lean hydrogen-air deflagration. Int J Hydrogen Energ 2014; 39(35): 20509-20515.

[7] Guo J, Sun XX, Rui SC, Hu KL, Wang CJ. Effect of ignition position on vented hydrogen-air explosions. Int J Hydrogen Energ 2015; 40(45): 15780-15788. 
[8] Proust C, Leprette E. The dynamics of vented gas explosions. Process Saf Prog 2010; 29(3): 231-235.

[9] Guo J, Wang CJ, Liu XY, Chen Y. Explosion venting of rich hydrogen-air mixtures in a cylindrical vessel with two symmetrical vents. Int J Hydrogen Energ 2017; 42(11):7644-7650.

[10] Lv X, Zheng L, Zhang Y, Yu M, Su Y. Combined effects of obstacle position and equivalence ratio on overpressure of premixed hydrogen-air explosion. Int $\mathbf{J}$ Hydrogen Energ 2016; 41(39):17740-17749.

[11] Schiavetti M, Marangon A, Carcassi M. Experimental study of vented hydrogen deflagration with ignition inside and outside the vented volume. Int J Hydrogen Energ 2014; 39(35):20455-20461.

[12] Kasmani RM. Vented gas explosions. University of Leeds, 2008.

[13] Guo J, Li Q, Chen DD, Hu HL, Shao K, Guo CM, Wang CJ. Effect of burst pressure on vented hydrogen-air explosion in a cylindrical vessel. Int J Hydrogen Energ 2015; 40(19):6478-6486.

[14] Holbrow P, Andrews S, Lunn GA. Dust explosions in interconnected vented vessels. J Loss Prevent Proc 1996; 9(1):91-103.

[15]Zhang Q, Jiang J, You M, Yu Y, Cui Y. Experimental study on gas explosion and venting process in interconnected vessels. J Loss Prevent Proc 2013; 26(6):1230 -1237.

[16] Liang Z. Scaling effects of vented deflagrations for near lean flammability limit hydrogen-air mixtures in large scale rectangular volumes. Int J Hydrogen Energ 2017; 42(10): 7089-7103.

[17] Iida N, Kawaguchi O, Sato GT. Premixed flame propagating into a narrow channel at a high speed, part 1: Flame behaviors in the channel. Combust Flame 1985; 60(3):245-255.

[18] Ponizy B, Leyer JC. Flame dynamics in a vented vessel connected to a duct: 1. Mechanism of vessel-duct interaction. Combust Flame 1999; 116(1-2): 259-271. 
[19] Ponizy B, Leyer JC. Flame dynamics in a vented vessel connected to a duct: 2. Influence of ignition site, membrane rupture, and turbulence. Combust Flame1999; 116(1-2): 272-281.

[20] Ferrara G, Willacy SK, Phylaktou HN, Andrews GE, Di Benedetto A, Salzano E, Russo G. Venting of gas explosion through relief ducts: interaction between internal and external explosions. $\mathbf{J}$ Hazard Mater 2008; 155(1-2): 358-368.

[21]Ponizy B, Henneton N, Claverie A, Veyssiere B. Detailed investigation of flame transmission from a vessel to a discharge duct. Combust Flame 2014;161(5):1348-1364.

[22] Guo J, Wang CJ, Liu XY. Experimental study on duct-vented explosion of hydrogen-air mixtures in a wide range of equivalence ratio. Ind Eng Chem Res 2016; 55(35): 9518-9523.

[23] Medvedev SP, Polenov AN, Khomik SV, Gelfand BE. Initiation of upstream-directed detonation induced by the venting of gaseous explosion. Proc Combust Ins 1994; 25(1): 73-78.

[24] Dorofeev SB, Bezmelnitsin AV, Sidorov VP. Transition to detonation in vented hydrogen-air explosions. Combust Flame 1995; 103(3): 243-246.

[25] Wang ZR, Pan MY, Jiang JC. Experimental investigation of gas explosion in single vessel and connected vessels. J Loss Prevent Proc 2013; 26(6):1094-1099.

[26] Lunn GA, Holbrow P, Andrews S, Gummer J. Dust explosions in totally enclosed interconnected vessel systems. J Loss Prevent Proc 1996; 9(1):45-58.

[27] Damazo J, Shepherd JE. Observations on the normal reflection of gaseous detonations. Shock Waves 2017; 27(5): 795-810.

[28] Igra O, Falcovitz J, Houas L, Jourdan G. Review of methods to attenuate shock/blast waves. Prog Aerosp Sci 2013; 58:1-35.

[29] NFPA 68. Standard on explosion protection by deflagration venting. 2007. 
[30] Li Q, Lu SX, Xu MJ, Ding YM Wang CJ. Comparison of flame propagation in a tube with a flexible/rigid obstacle. Energ Fuel 2016; 30(10):8720-8726.

[31] Heidari A, Wen JX. Flame acceleration and transition from deflagration to detonation in hydrogen explosions. Int J Hydrogen Energ 2014; 39(11):6184-6200.

[32] Johansen CT, Ciccarelli G. Visualization of the unburned gas flow field ahead of an accelerating flame in an obstructed square channel. Combust Flame 2009; 156(2):405-416. 